\title{
Utilization of diabolo-shaped covered biliary stents in a refractory esophagus- colonic anastomotic stricture
}

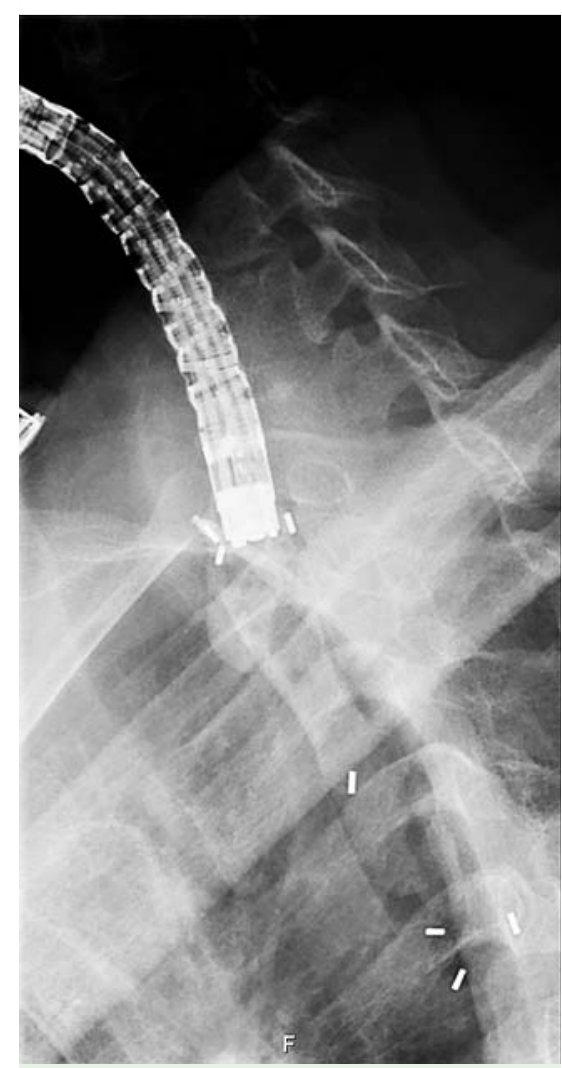

Fig. 1 Radiologic view showing a biodegradable esophageal stent placed to treat a refractory esophagus-colonic stricture.

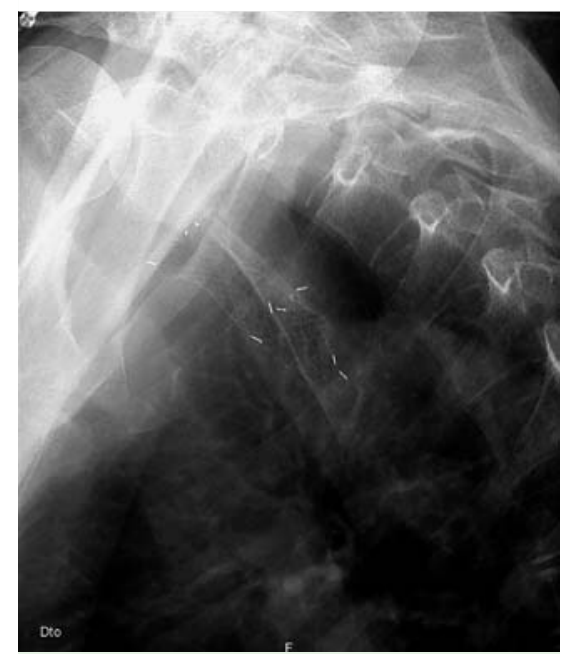

Fig. 2 Radiologic view of a diabolo-shaped, covered, biliary, self-expandable metallic stent placed at the stricture site.

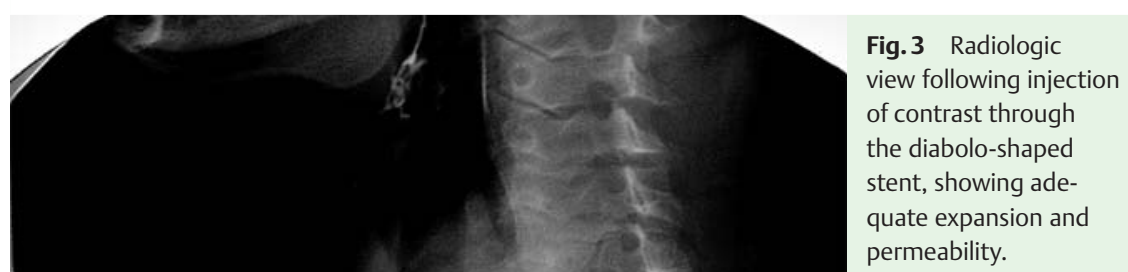

A 54-year-old man underwent a proximal gastrectomy with partial esophagectomy to treat a carcinoma of the cardia 5 years ago. A persistent postoperative fistula of the esophago-gastric anastomosis occurred, which required a second surgery 4 years ago during which a colon interposition was performed. After surgery, stricture of the esophagus-colonic anastomosis developed $2 \mathrm{~cm}$ distal from the upper esophageal sphincter, causing grade 3 dysphagia for which the patient underwent multiple dilations with Savary-Gilliard bougies. As the stenosis was deemed refractory to serial dilations, a biodegradable esophageal stent (BD stent 019-10A23/18/23-060; SX-ELLA, Hradec Kralove, Czech Republic) was placed 1 year ago (৫ Fig. 1).
Although transient improvement was noticed, the patient experienced recurrent dysphagia 1 month later and required further dilations 4 months later. Hence, a $4 \mathrm{~cm}$ diabolo-shaped, covered, biliary, self-expandable metallic stent (SEMS; Hanarostent BCF-10-040-180; M.I. Tech Co., Seoul, Korea), $10 \mathrm{~mm}$ in diameter and with flares $5 \mathrm{~mm}$ long and $24 \mathrm{~mm}$ in diameter, was placed under direct and fluoroscopic view ( Fig.2, $\odot$ Fig.3, Fig.4) using a therapeutic channel endoscope (GIF 2T130; Olympus, Tokyo, Japan). The stent was well tolerated and the patient noticed an immediate substantial improvement from grade 3 to grade 1 dysphagia.

The stent was exchanged three more times at 8-week intervals using the proxi- 

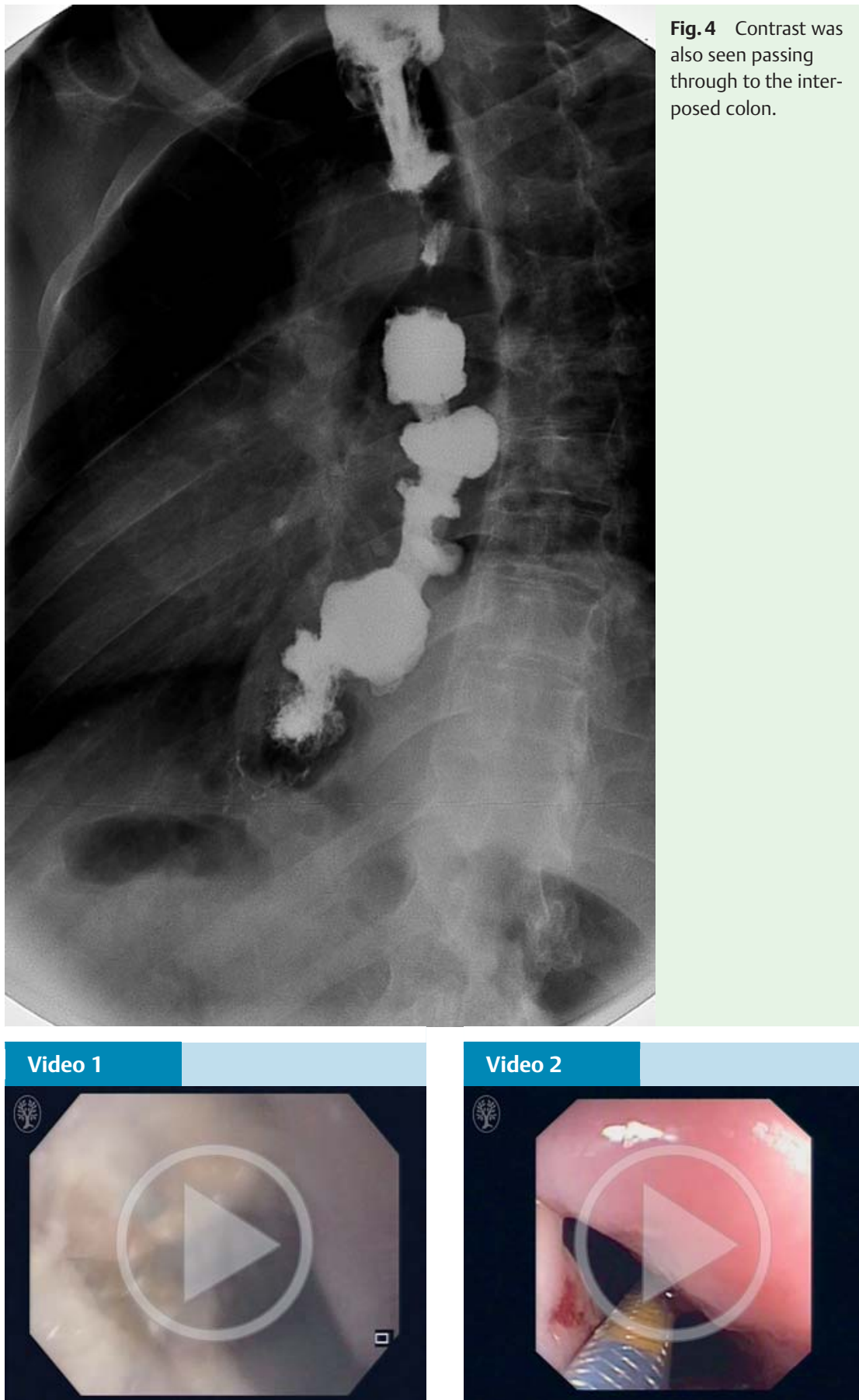

Endoscopic video showing the removal of a diabolo-shaped self-expandable metallic stent (SEMS) placed to treat a refractory esophaguscolonic stricture near the upper esophageal sphincter. The SEMS was removed by pulling the lasso with a snare.

mal lasso for stent removal; increasing improvement in the diameter of the stenosis was observed. The final two procedures were performed under direct view only ( Fig.5, $\bullet$ Fig.6, Video 1, - Video 2). The patient remained asymptomatic after removal of the final stent.

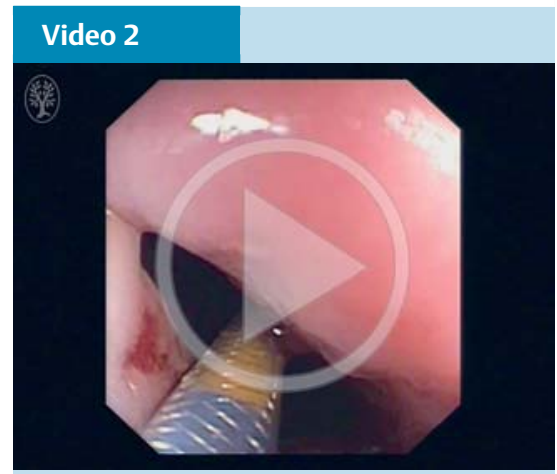

A new self-expandable metallic stent was placed in the stenotic stricture under exclusive endoscopic view.

Diabolo-shaped stents have important technical advantages for stenoses near the upper esophageal sphincter, as they have shorter and larger flares that limit patient intolerance and prevent migration, respectively. Furthermore, the diameter of the delivery device permits its

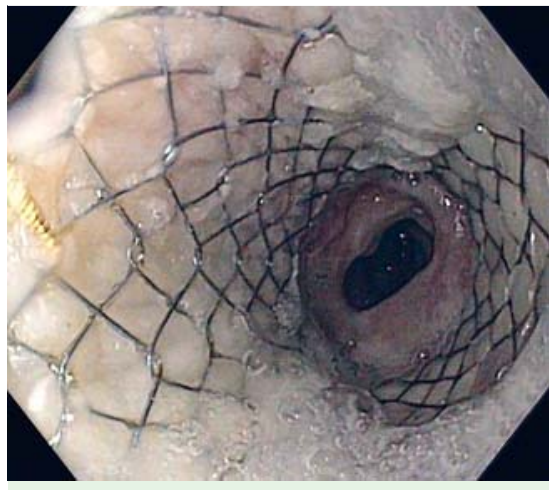

Fig. 5 Endoscopic view showing easy passage of the endoscope inside the stent.

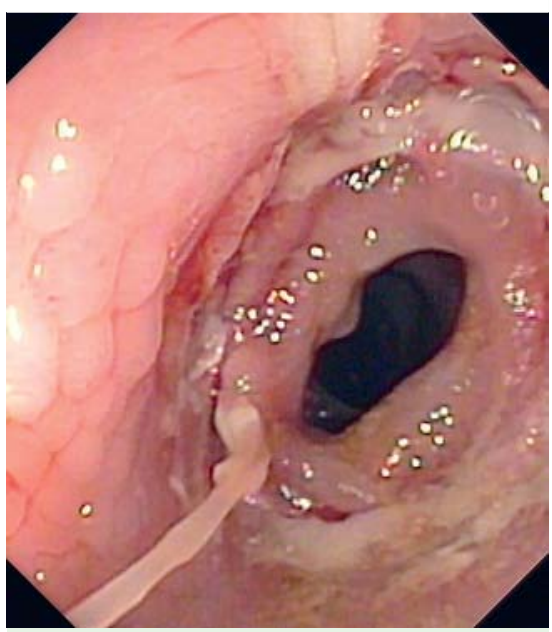

Fig. 6 Endoscopic view showing the dilated stricture after removal of the stent.

placement under direct endoscopic view using a therapeutic endoscope, resulting in accurate positioning [1 -4].

Endoscopy_UCTN_Code_TTT_1AO_2AZ

Competing interests: None

Rolando Pinho, Luísa Proença, Ana Ponte, Joana Silva, Jaime Rodrigues, Mafalda Sousa, João Carvalho

Gastroenterology Department,

Centro Hospitalar de Vila Nova de Gaia, Vila Nova de Gaia, Portugal

\section{References}

1 Binmoeller KF, Shah J. A novel lumen-apposing stent for transluminal drainage of nonadherent extraintestinal fluid collections. Endoscopy 2011; 43: 337-342

2 Gornals JB, De la Serna-Higuera C, SánchezYague $A$ et al. Endosonography-guided drainage of pancreatic fluid collections with a novel lumen-apposing stent. Surg Endosc 2013; $27: 1428-1434$ 
3 Itoi T, Binmoeller KF. EUS-guided choledochoduodenostomy by using a biflanged lumen-apposing metal stent. Gastrointest Endosc 2014; 79 : 715

4 Majumder S, Buttar N, Gostout $C$ et al. Lumen-apposing covered self-expanding metal stent for management of benign gastrointestinal strictures. Endosc Int Open 2016; 04: E96-E101

\section{Bibliography}

Dol http://dx.doi.org/

10.1055/s-0042-106964

Endoscopy 2016; 48: E174-E176

(c) Georg Thieme Verlag KG

Stuttgart · New York

ISSN 0013-726X
Corresponding author

Rolando Taveira Pinho, MD

Serviço de Gastrenterologia

Centro Hospitalar de Vila Nova de Gaia

Rua Conceição Fernandes

4434-502 - Vila Nova de Gaia

Portugal

Fax: +351-227-868369

rolandopinho@gmail.com 